2016-07-30

\title{
Creating Local Pathways in University Teacher Education: Planting the Seed
}

\author{
Lynch, TJ
}

http://hdl.handle.net/10026.1/6372

10.1007/978-3-319-31667-3_3

Springer International Publishing

All content in PEARL is protected by copyright law. Author manuscripts are made available in accordance with publisher policies. Please cite only the published version using the details provided on the item record or document. In the absence of an open licence (e.g. Creative Commons), permissions for further reuse of content should be sought from the publisher or author. 


\title{
Creating Local Pathways in University Teacher Education: Planting the Seed
}

\begin{abstract}
This chapter shares the very beginnings of the partnership journey, metaphorically as a seed which incrementally developed as opportunities were presented. The university classes for the semester swimming unit EDF2611 were redesigned to create a pathway with the swimming and water safety course qualification-Swim Australia Teacher. Careful mentoring enabled the implementation of 'hands on' practical teaching and learning experiences for the university Initial Teacher Education preservice teachers, quality swimming lessons at no cost for local primary school children (from a disadvantaged socio-economic region), and professional development for teachers.
\end{abstract}

This partnership journey began small, metaphorically as a seed which incrementally developed as opportunities were presented. It was always the intention of the programme leader to manage partnerships, and consequently, maintain quality assurance and suitability for university ITE. The long-term plan was for programme sustainability involving more schools, children, and a wider range of health and physical education (Fig. 2.1). Discussion of the community collaboration partnerships is in reference to the International Civil Society Centre 'Nine building blocks for successful partnerships' (2014, p. 14).

(C) The Editor(s) (if applicable) and The Author(s) 2016

T. Lynch, The Future of Health, Wellbeing and Physical Education, DOI 10.1007/978-3-319-31667-3_3 
The original problem identified by the author was that university students were developing knowledge and skills within the unit EDF2611 'Experiencing aquatic environments', yet were not recognised within the industry, and therefore, not by the state education institute. Subsequently, students were required to spend $\$ 350$ in addition to their university fees to gain a swimming and water safety instructor qualification. This requirement was mandated by the VIT (VIT 2008) for teacher registration as a Primary School Physical Education teacher. This qualification was valued by the programme leader, especially within the Australian context. Furthermore, the programme leader maintained the belief metaphorically speaking that practice sessions should resemble as much as possible the real game. Hence, applying theories in practice provided the challenges necessary for preparation of quality teachers.

\section{ACTORS}

\section{Leadership}

Swim instructor providers were contacted to investigate the possibility of ITE pre-service teacher 'recognition of prior learning' (RPL) for the swimming and water safety knowledge and skills underpinning EDF261l. Furthermore, recognition of a possible pathway between the content covered within EDF2611 lectures and workshop, and the RTO's swimming and water safety industry units of competency. This unit/module at the Monash University Gippsland campus previously required that students complete swimming and water safety accreditation during their own time and present evidence of the qualification. The leader was a pioneer in what appeared to be a common sense connection and socially just cause within the socio-economically disadvantaged region.

Correspondence with RTO providers was initiated in January 2011 through phone calls and e-mails. It was anticipated by the leader that all providers would share similar swimming and water safety educational aspirations. AUSTSWIM informed the programme leader, who had held a swimming and water safety AUSTSWIM Teacher of Swimming and Water Safety Teacher qualification for over ten years and had various experiences of teaching swimming and water safety spanning from early years to higher education, that he could complete Course Presenter Training, qualifying him for training AUSTSWIM swim instructors (pre-service teachers). The prerequisites for a Course Presenter included: 
There were setbacks and barriers to overcome which will be discussed in more detail in Chap. 10. As a result of the programme evaluation, the leader decided to liaise with the primary schools in future collaborations rather than allowing this to be the responsibility of the pool swimming instructors.

Early responses from stakeholders suggested that they were appreciative of the learning experience that the swimming lessons provided, and that partnership efforts should continue. Hence, the initial stages of partnership were established and the goal for swimming lessons achieved. The children from the local primary schools were excited, evidenced by attendance and preparation for the lessons, and smiles on faces. Parents also attended lessons to support their children, and many thankful comments were made by teachers, teaching assistants, parents, and the children.

As previously mentioned, the programme leader deliberately began the initiative with low-set goals. This alleviated any pressure on teachers and schools. Furthermore, it increased opportunities for programme success and stakeholder commitment. Minimising pressure and demands was essential for building trust with schools: principals, teachers, and parents. Furthermore, all publications and discussions held were transparent, and feedback from stakeholders and readers were at all times welcome.

This initial community collaborative effort assisted with building relations for future partnerships. The next community collaboration involved six rural primary schools during semester 1, 2012 (Chap. 7). Not only was sport used to build partnerships but also to deliver quality health and physical education lessons, again offering children sporting opportunities that they may otherwise not receive. Hence, relations with the sports centre and two of the local primary schools continued to grow the following year.

\section{REFERENCES}

Australian Government. (2011). Training.gov.au a joint initiative of Australian state and territory governments. Retrieved from http://training.gov.au/ Organisation/Details/

Australian Swimming Coaches and Teachers Association (ASCTA). (2010). Course presenter's kit. Beerwah, QLD: Author.

Australian Swimming Coaches and Teachers Association (ASCTA). (2011). Swim Australia Teacher (SAT) course evaluations summary. Beerwah, QLD: Author. Badenoch, C. (2015, February 27). Vice President for Global Advocacy-World Vision, United Nations Economic and Social Council (ECOSOC) special event 
panelist-2015 Multi-stakeholder partnerships: Making them work, for the Post2015 Development Agenda'. Retrieved from http://webtv.un.org/watch/ multi-stakeholder-partnerships-making-them-work-for-the-post-2015development-agenda-economic-and-social-council/4084615948001

International Civil Society Centre. (2014). Multi-stakeholder partnerships: Building blocksfor success. Retrieved from https://icscentre.org/downloads/14_10_02_ Multi-Stakeholder_Partnerships.pdf

Lynch, T. (2012a). Creating pathways for swimming and water safety within Teacher education: a university perspective. Swimming in Australia: Journal of the Australian Swimming Coaches and Teachers Association, 28(3), 34-36.

Lynch, T. (2012b). Rips, currents and snags: Investigating the complexities of teaching swimming and water safety within primary schools. Swimming in Australia: Journal of the Australian Swimming Coaches and Teachers Association, 28(3), 48-52.

Lynch, T. (2012c). Rips, currents and snags: Investigating the delivery of educational goals for young Australians in the region of Gippsland, Victoria. Australian and International Journal of Rural Education, 22(3), 1-18.

Lynch, T. (2012d). Swimming and water safety: a school teacher's perspective. Swimming in Australia: Journal of the Australian Swimming Coaches and Teachers Association, 28(3), 42-45.

Lynch, T. (2014). Investigating a win, win situation: delivering quality swimming experiences for children in local primary schools within the Gippsland region, via teacher education. In A. Gunstone (Ed.), Developing sustainable education in regional Australia (pp. 117-132). Melbourne, Australia: Monash University Publishing.

Monash University Faculty of Education. (2011a). EDF2611 experiencing aquatic environments unit evaluation report. Retrieved from http://emuapps.monash. edu.au/unitevaluations/wr/uewr_rpl_public.jspjit_cd= EDF2611\&ref_unit_cd=no_ref_cd

Monash University Faculty of Education. (2011b). EDF2611 experiencing aquatic environments Gippsland student evaluations of teaching unit (SETU) semester one qualitative data. Melbourne, VIC: Author.

Victorian Institute of Teaching (VIT). (2008). Victorian institute of teaching specialist area guidelines. Retrieved from http://www.vit.vic.edu.au/finditfast/ Teacher-education-programs/Pages/Assessmentofqualifications.aspx

Victorian Institute of Teaching (VIT). (2015). Victorian institute of teaching specialist area guidelines. Retrieved from http://www.vit.vic.edu.au/media/documents/imported-files/publications-and-forms/forms/Specialist _Area_Guidelines_2015.pdf 